Technical Notes

\title{
Simplified theory of Archimedean screws
}

\section{Théorie simplifiée de la vis d'Archimède}

\author{
GERALD MÜLLER, (IAHR Member), University of Southampton, School of Civil Engineering and the Environment, \\ Highfield, Southampton, SO17 1BJ, UK. Tel.: +44 23 8059 2442; fax: +44 2380 677519; e-mail: g.muller@soton.ac.uk \\ (author for correspondence)
}

JAMES SENIOR, University of Southampton, School of Civil Engineering and the Environment, Highfield, Southampton, SO17 1BJ, UK. Tel.: +44 238059 2496; fax: +442380677519; e-mail: js1301@ soton.ac.uk

\begin{abstract}
The Archimedean screw pump is one of the oldest hydraulic machines. Today, it is employed in pumping as well as - operating in reverse - in an energy conversion role. Despite its age, no consistent theory links the screw's geometry with its mechanical efficiency. Based on geometrical parameters and an idealised energy conversion process for one turn of the helix, a theoretical model is developed and compared with experimental results. Theoretical maximum efficiencies were found to be a function of the screw's geometry and matched reported experimental results well. The statement that the efficiency of a screw is a function of losses only could not be confirmed.
\end{abstract}

\section{RÉSUMÉ}

La pompe à vis d'Archimède est l'une des machines hydrauliques les plus anciennes. Aujourd'hui, elle est utilisée en pompage et également en fonctionnement inverse - dans un rôle de conversion d'énergie. En dépit de son âge, aucune théorie établie ne lie la géométrie de la vis à ses performances mécaniques. Sur la base des paramètres géométriques et d'un processus idéalisé de conversion d'énergie pour un tour de la spirale, un modèle théorique est développé et comparé aux résultats expérimentaux. Les rendements maxima théoriques se sont avérés être fonction de la géométrie de la vis et bien concorder avec des résultats expérimentaux. L'idée que le rendement d'une vis est seulement fonction des pertes ne serait pas confirmée.

Keywords: Archimedean screw, Hydraulic screw, Hydropower converter, Low head hydropower, Theory

\section{Introduction}

The Archimedean screw in the pumping role has been known since antiquity. It consists of an axis with helical blades, lying in a channel with a semi-circular or even closed circular cross section (Fig. 1). Recently, the Archimedean screw has also found a new application operating in reverse as an energy converter for low head differences (Hellmann 2003).

Since this appears to be an important new development, the following work focuses on the role as power converter, the analysis can however easily be transformed to determine pump efficiency. Although the Archimedean screw has been known for a long time, there appears to be no theory which relates the available (or, in the pumping role, the required) energy to the screw geometry and determines its mechanical efficiency limits. Published technical information deals mostly with empirical design rules, and the optimization of the screw's geometry with respect to the maximum volume that can be contained. Optimum design ratios are given as a balance between increasing efficiencies and increasing costs (Nagel and Radlik 1988, Rorres 2000). The efficiency of a hydraulic screw is perceived to be a function of mechanical, hydraulic and leakage losses only (Nagel and Radlik 1988). Measurements of the Archimedean screw as an energy converter showed the effect of inflow water level to diameter, and gave efficiencies between 79 and $84 \%$, making this an interesting alternative for turbines in low head hydropower applications (Brada and Radlik 1996, Brada 1999, Hellmann 2003).

\section{Theory}

It is generally assumed that the water weight enclosed by the screw's blades drives the screw, (Nagel and Radlik 1988, Brada 1999). Assuming no losses, all potential energy contained in the flow can be extracted giving such a machine the theoretical maximum efficiency of $100 \%$. Most of the water weight in the 


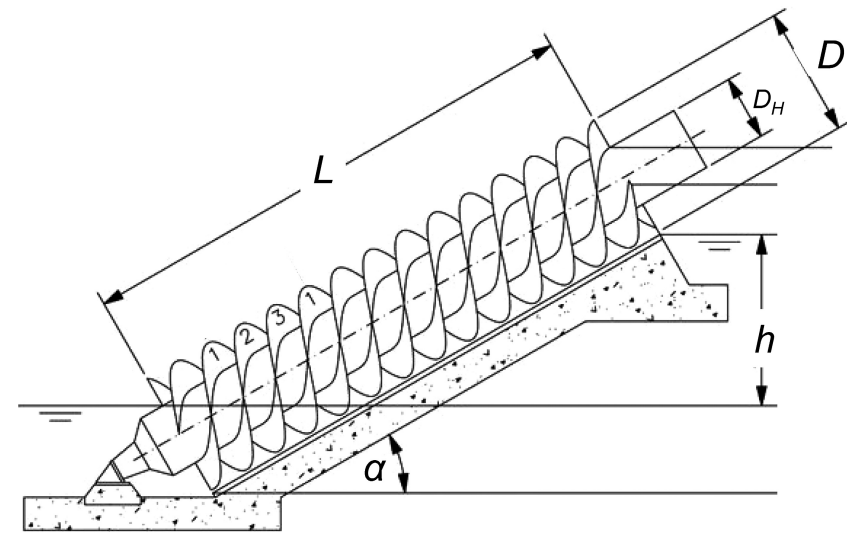

(a)

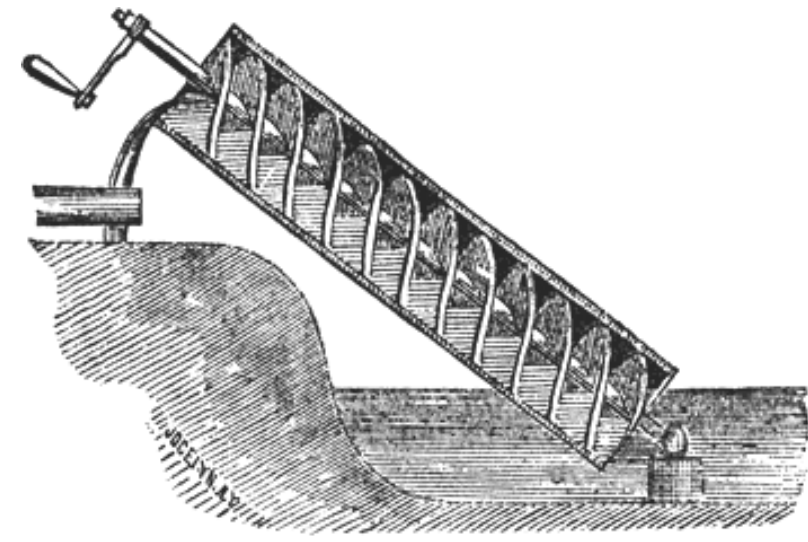

(b)

Figure 1 The Archimedean screw: (a) side elevation, (b) internal water levels (www.wikipedia.de)

Archimedean screw however rests on the trough, which does not move (Fig. 1). Power equals force $\times$ velocity, and since the velocity vector of the rotating screw acts tangentially to the screw, only a small part of the water weight enclosed in the screw (the part which is resting on the inclined outer section of the blade) contributes to energy conversion. This is unlike the water in the cells of an overshot water wheel, where the direction of the weight force of the complete water mass coincides with the downward direction of the cell movement. The contribution of the weight force is therefore neglected.

The screw's blades however are exposed to the hydrostatic pressure from the enclosed water. From the screw's geometry, information is drawn to develop a theoretical model using the following simplifications:

1. The screw is idealized as a set of moving, vertical blades set with an angle $\beta$ with the axis of rotation as shown in Fig. 2.

2. Gap losses are initially neglected.

3. The middle strip as shown in Fig. 3(a) is considered as representative.

4. The radius $R$ is significantly larger than the submerged depth of the blade.

5. The hub diameter is small.

A screw has a head difference $h$, a total length $L$ and $m$ turns of the helix with a horizontal distance $l$ in contact with the water. The longitudinal section in Fig. 2(a) shows the water levels inside the screw; between two blades there exists a head difference so that a horizontal hydrostatic force develops. Figure 2(b) indicates hydrostatic pressures on the inclined blades; with an upstream pressure $p_{1}$ larger than the downstream (counteracting) pressure $p_{2}$ acting normally on the blades. Only the component in the direction of the screw rotation however will contribute to the work.

Figure 3(a) shows the middle strip ' $s$ ', which has a projected area $A_{x}$ in $x$-direction, and which is assumed to be representative for, or the average of, the wetted area of the screw. In Fig. 3(b), the hydrostatic pressure acting on the inclined blade is shown. In accordance with basic hydrostatics, the pressure $p_{x}$ in the axial direction is the same as pressure $p_{z}$ acting normal to the axis, and the pressure $p$ normal to the blade, whereby the area of pressure in the $z$ direction is $A_{z}=A_{x} \tan \beta$. Figure 3(b) shows the velocity vectors, where the tangential velocity in $z$ direction $v_{z}=v_{x} / \tan \beta$. The total work per unit area $P_{\text {unit }}$ then is

$$
P_{\text {unit }}=p_{z} \cdot A_{z} \cdot v_{z}=p_{x} \cdot A_{x} \cdot \tan \beta \cdot \frac{v_{x}}{\tan \beta}=p_{x} \cdot A_{x} \cdot v_{x}
$$

The work done by the screw therefore can be expressed as a function of cross-sectional area $A_{x}$ and the downward/longitudinal blade velocity $v_{x}$. For the analysis, the screw itself is replaced by $m$ individual rotating blades of water depth $d_{0}+\Delta d$ upstream, and a downstream depth of $d_{0}$, whereby the water inside the screw must have the same horizontal velocity $v_{1}=v_{x}$ as the blade. The power is generated by the hydrostatic pressure difference and the horizontal screw velocity $v_{1}$. This power generation mechanism

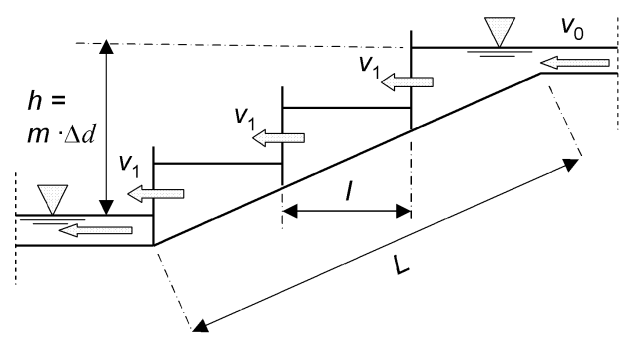

(a)

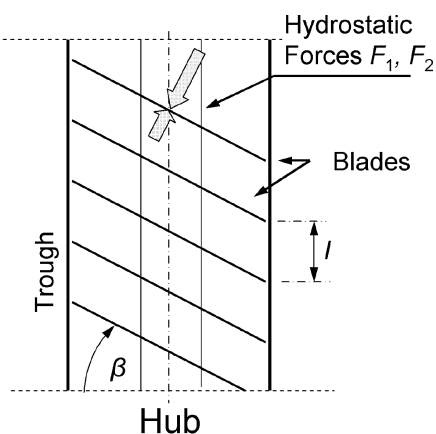

(b)

Figure 2 Idealized Archimedean screw: (a) side view, (b) plan view of submerged blade 


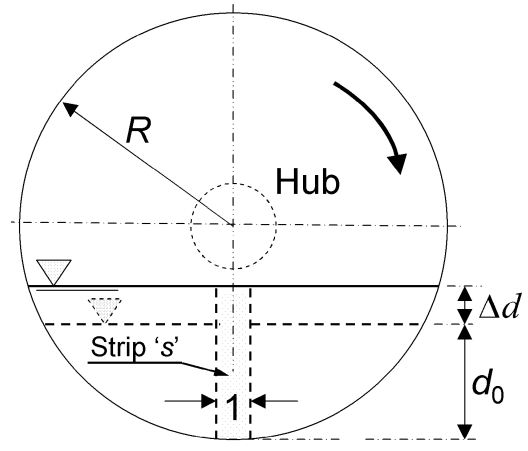

(a)

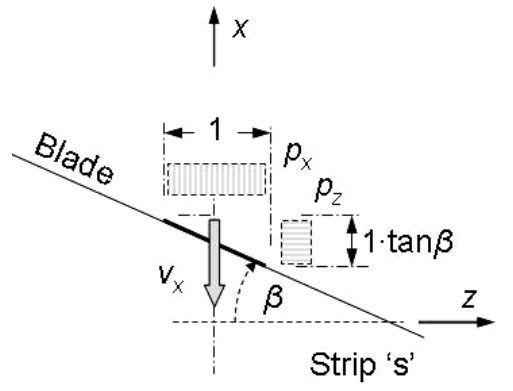

Hydrostatic pressure

(b)

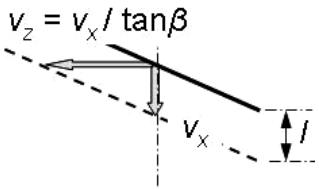

Velocity vectors

(c)

Figure 3 Pressure and velocity components: (a) centre strip 's', (b) hydrostatic pressures, (c) velocity vectors

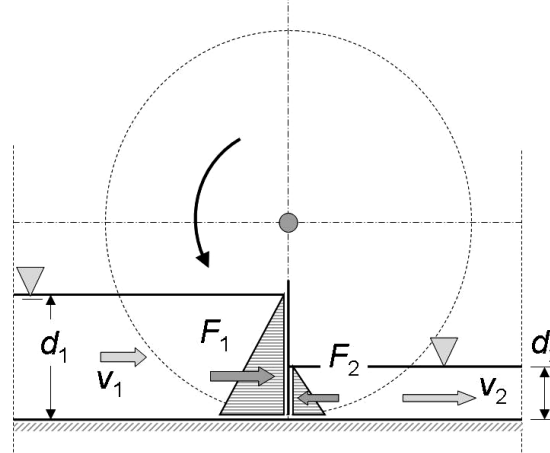

(a)

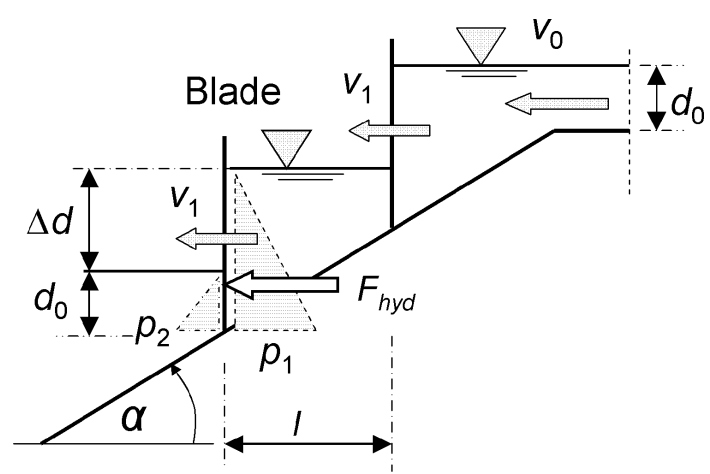

(b)

Figure 4 Principle of power generation (a) hydrostatic pressure wheel, (b) forces acting on individual screw blade

is envisaged similar to the Hydrostatic Pressure Machine (HPM) described by Senior et al. (2008). The HPM in its simplest form consists of a wheel of radius $R$, whose blades also act as a weir, creating a head difference (Fig. 4(a)). The hydrostatic pressure difference between up- and down-stream acts on the blades which move with the velocity $v_{1}$ of the upstream water flow. The efficiency becomes a function of the ratio of up- and down-stream water depths $d_{1}$ and $d_{2}$, where $\eta_{H P W}=\left(1+d_{2} / d_{1}\right) / 2$.

A detailed view of one blade of the Archimedean screw is shown in Fig. 4(b). The differential water levels between the up- and down-stream sides of each blade generate a hydraulic force $F_{\text {hyd }}$, moving with the screw speed $v_{1}$, generating a power $P_{s}=F_{\text {hyd }} \times v_{1}$. With a trough angle $\alpha$ relative to the horizontal, and a distance $l$ between two individual blades, the water depth increases by $\Delta d=l \tan \alpha=(L / m) \tan \alpha$, or

$$
\Delta d=\frac{h}{m}
$$

The hydrostatic force $F_{\text {hyd }}$ for a rectangular section of unit width is then determined to

$$
F_{h y d}=\frac{\left(d_{0}+\Delta d\right)^{2}-d_{0}^{2}}{2} \cdot \rho \cdot g
$$

The approach flow velocity $v_{1}$ to the screw is smaller than the entry velocity $v_{0}$

$$
v_{1}=\frac{d_{0}}{d_{0}+\Delta d} v_{0}
$$

Force $\times$ velocity gives the power produced $P_{\text {blade }}=F_{\text {hyd }} v_{1}$. With $m$ blades, the total power becomes $P=m P_{\text {blade }}$. The available hydraulic power $P_{h y d}$ therefore is

$$
P_{h y d}=\rho \cdot g \cdot Q \cdot h=\rho \cdot g \cdot d_{0} \cdot v_{0} \cdot m \cdot \Delta d
$$

With $n=d_{0} / \Delta d$ the theoretical efficiency $\eta_{t h}$ becomes

$$
\eta_{t h}=\frac{P}{P_{h y d}}=\frac{2 n+1}{2 n+2}
$$

Equation (6) implies that the efficiency is independent of screw speed, and only a function of its geometry, including the inflow depth, the screw angle and the number of turns/head drop between two screw turns. Equation (6) also gives a minimum efficiency. For $n \rightarrow 0$ or $d_{0} \rightarrow 0$, i.e. if the cells are not completely filled, $\eta_{\text {th } \min }=0.5$.

\section{Comparison with experimental results}

Only the test series of Brada (1999) on Archimedean screws working as energy converters is known to the authors, with the following parameters: Length $L=5.340 \mathrm{~m}$, Angle $\alpha=26$ degrees, Diameter $D=1.050 \mathrm{~m}$, Head difference $h=2.350 \mathrm{~m}$, helix turns $m=14$, Inflow depths $d_{0}=0.15$ to $0.5 \mathrm{~m}$. Discharges varied from $60 \mathrm{l} / \mathrm{s}$ for $d_{0}=0.15 \mathrm{~m}$, to $320 \mathrm{l} / \mathrm{s}$ for $d_{0}=0.5 \mathrm{~m}$. In a real screw, leakage occurs, which can be determined for Archimedean screws with an empirical formula of Nagel and Radlik (1988). 


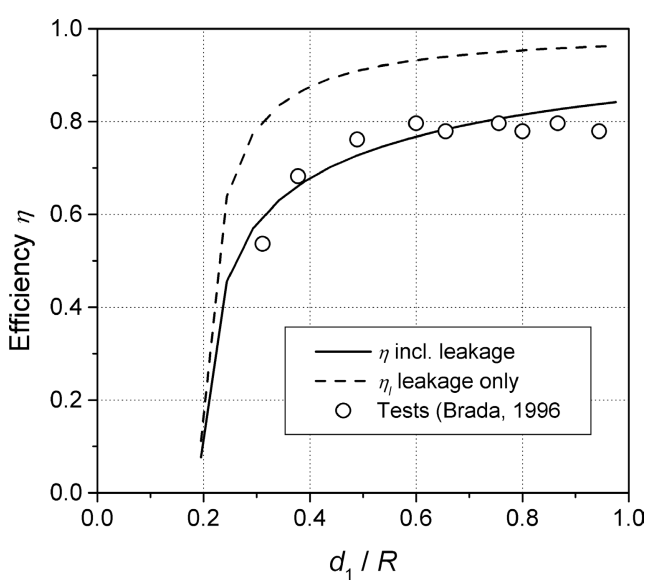

Figure 5 Efficiency $\eta$ as function of $d_{0} / R$

For a given diameter $D$, and a gap width $s$, the leakage volume $Q_{l}$ becomes

$$
Q_{l}=2.5 \cdot s \cdot D \cdot \sqrt{D}
$$

provided the gap width $s \leq 0.0045 D^{1 / 2}$. This results in $s=$ $4.6 \mathrm{~mm}$ and $Q_{l}=0.012 \mathrm{~m}^{3} / \mathrm{s}$, corresponding to $20 \%$ of the minimum discharge of $60 \mathrm{l} / \mathrm{s}$, and $3.8 \%$ of the maximum discharge of $320 \mathrm{l} / \mathrm{s}$. In the literature, the efficiency $\eta_{l}$ is often described as being determined by leakage losses (e.g. Nagel and Radlik 1988)

$$
\eta_{l}=1-\frac{Q_{l}}{Q}
$$

Figure 5 shows the efficiencies calculated with Eq. (8), the experimental results of Brada (1999) and the overall efficiencies $\eta$ from Eq. (6) corrected for leakage with $\eta=\eta_{t h} \cdot \eta_{l}$.. Equation (8) overestimates efficiencies significantly; in addition this equation does not account for the effects of geometry. The leakage corrected overall efficiency $\eta$ fits the data well.

The efficiency of Archimedean screw is not a function of the losses only, as was assumed previously, but also of the screw geometry. Figure 6 shows the efficiency as a function of screw angle and number of turns indicating that efficiency increases with decreasing angle and increasing number of turns. This

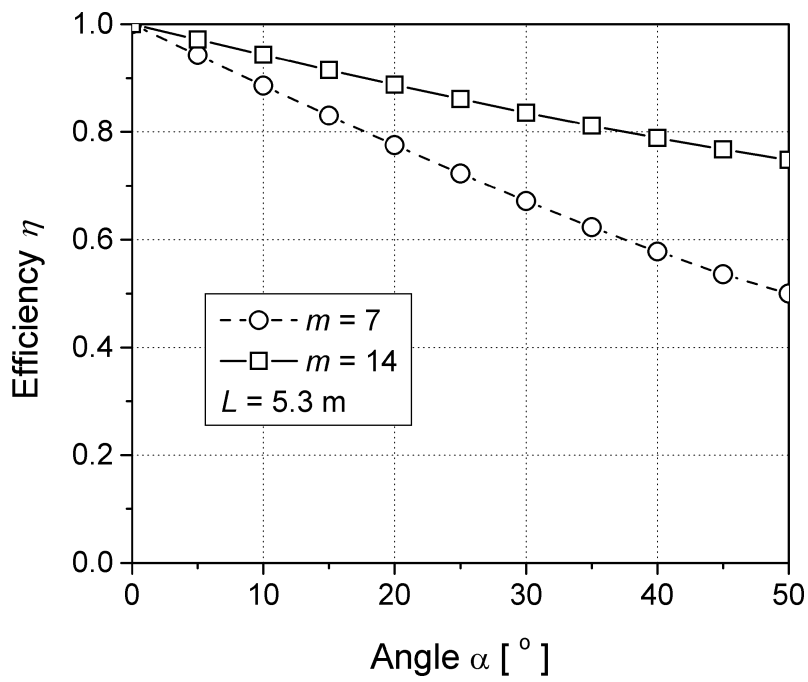

Figure 6 Theoretical efficiency as function of angle and number of turns, $\eta=f(\alpha, m)$ implies that in particular for steeper angles a higher number of turns is desirable. The theory further suggests that in order to maintain high efficiencies, the upstream water level should be kept constant and high compared with the radius. Shallower angles for the screw give higher efficiencies, although they result in a larger construction effort and subsequently higher costs.

\section{Conclusions}

- The efficiency of Archimedean screws is a function of geometry and losses.

- For each screw geometry, an upper limit for efficiency exists as a function of leakage losses and blade geometry (angle, the number of turns and the ratio of inflow depth and radius).

- Efficiency increases with decreasing head drop between turns (increasing number of turns, decreasing screw angle with the horizontal), and with increasing ratio of inflow depth and radius.

\section{Acknowledgements}

The research leading to these results has received funding from the European Community's Seventh Framework Programme (FP7/2007-2013) under grant agreement $\mathrm{n}^{\circ} 212423$.

\section{References}

Brada, K., Radlik, K.-A. (1996). Water screw motor for micropower plant. 6th Intl. Symp. Heat exchange and renewable energy sources, 43-52, W. Nowak, ed. Wydaw Politechniki Szczeciñskiej, Szczecin, Poland.

Brada, K. (1999). Wasserkraftschnecke ermöglicht Stromerzeugung über Kleinkraftwerke [Hydraulic screw generates electricity from micro hydropower stations]. Maschinenmarkt Würzburg, Mitteilung 14, 52-56. http://www.maschinenmarkt.vogel.de/index.cfm?pid=5156\&pk=303 [in German].

Hellmann, H.D. (2003). Gutachten zur Wirkungsgradbestimmung einer Wasserkraftschnecke Fabrikat Ritz-Atro [Report on determination of hydraulic screw efficiency manufactured by Ritz-Atro Ltd.] Fachbereich Maschinenbau und Verfahrenstechnik, Technical University, Kaiserslautern, Germany (http://www.ritz-atro.de/2006/downloads/Wasserkraft_GB. pdf) [in German].

Müller, G., Kauppert, K. (2004). Performance characteristics of water wheels. J. Hydr. Res. 42(5), 42-48.

Nagel, G., Radlik, K.-A. (1988). Wasserförderschnecken [Water lifting screws] Bauverlag, Wiesbaden/Berlin [in German].

Rorres, C. (2000). The turn of the screw: Optimal design of the Archimedean screw. J. Hydr. Engng. 126(1), 72-80.

Senior, J., Wiemann, P., Müller, G. (2008). The rotary hydraulic pressure machine for very low head hydropower sites. Proc. Hidroenergia 2008, Bled/Slovenia, European Small Hydropower Association, Session 5B(1). 